\title{
RASGOS GRÁFICOS DE LAS INSCRIPCIONES EN LA PROVINCIA DE SALAMANCA
}

\section{GRAPHIC FEATURES OF MEDIEVAL INSCRIPTIONS FROM SALAMANCA PROVINCE}

\author{
Natalia Rodríguez SuÁReZ \\ Universidad Isabel I, Instituto de Estudios Medievales León. \\ nrods@unileon.es
}

Recibido: $14 / 10 / 2015$

Aceptado: 5/12/2015

RESUMEN: El presente artículo pretende mostrar las particularidades gráficas que presentan las inscripciones medievales de la provincia de Salamanca. Dicho análisis gráfico ofrece, de manera conjunta, la evolución gráfica de la escritura publicitaria medieval en esta zona y permite ponerlo en conexión con otras, tanto nacionales como internacionales, ayudando así a fijar las particularidades gráficas del panorama epigráfico español.

PALABRAS CLAVE: Epigrafía, Epigrafía medieval, escritura medieval, Salamanca, escritura visigótica, escritura carolina, escritura gótica, escritura prehumanística.

ABSTRACT: This article aims to show the graphic peculiarities of medieval inscriptions in the province of Salamanca. This analysis provides the graphic evolution of medieval advertising writing in this area and its connection with other national and international graphic particularities, contributing to set the graphic particularities of the Spanish epigraphic situation.

KEYWORDS: Epigraphy, medieval Epigraphy, medieval writing, Salamanca, Visigothic writing, Caroline writing, Gothic writing, Prehumanistic writing.

Hace tiempo que se viene definiendo a la inscripción por su función publicitaria, esto es, transmitir información de cualquier tipo de manera pública y permanente ${ }^{1}$. Ese carácter publicitario determina cómo se debe hacer una inscripción,

${ }^{1}$ M. GÓMEZ MORENO (1953). El concepto de la epigrafia. Consideraciones sobre la necesidad de su ampliación. Discursos leídos ante la Real Academia de la Historia por los señores D. Joaquín $M^{a}$. de Navascués y de Juan y D. Manuel Gómez-Moreno y Martínez en la recepción pública del 
qué técnicas ha de utilizar, así como su emplazamiento para conseguir eficazmente la publicidad. Por ello, dentro de los objetos escritos, la inscripción presenta ciertas particularidades donde el texto y la escritura están asociados al espacio y a la materia. La impaginación del texto o los recursos gráficos revelan ese deseo de llamar la atención del viandante (viator) para que se convierta en lector ${ }^{2}$.

El estudio de la escritura epigráfica de la Edad Media requiere un análisis de todos los elementos externos. Los caracteres gráficos, variables según las épocas, deben estudiarse más allá de una descripción de letras, para ahondar en todo el acervo cultural que el conjunto epigráfico ofrece. Por ello, abordar el estudio de la escritura epigráfica no debe limitarse a una descripción somera de los caracteres alfabéticos, deben analizarse las abreviaturas, los nexos y otros recursos gráficos como las inserciones, los cruzamientos o los signos complementarios. Éste es el objeto del trabajo que a continuación se presenta, tomando como hilo conductor las inscripciones medievales salmantinas, para ofrecer al especialista un panorama general de esta provincia, analizando, a través de los rasgos externos, las particularidades epigráficas de esta zona.

Como viene siendo habitual las inscripciones medievales se agrupan atendiendo a sus rasgos gráficos en cuatro etapas: la visigótica, la carolina, la gótica y la prehumanística.

\section{INSCRIPCIONES VISIGÓTICAS}

La cronología de las inscripciones visigóticas abarca, de manera general, el periodo comprendido desde el siglo VIII hasta la sustitución de la misma por la escritura carolina, que aparece perfectamente asentada en el territorio hispánico en el siglo XII. Sin embargo, debemos hace notar que tanto la introducción como la decadencia y sustitución de la escritura visigótica, -al igual que sucede con la mayoría de las escrituras- es variable según las zonas, urbanas o rurales, en función de las tendencias culturales, más o menos conservadoras o según las particularidades del taller que realiza la inscripción. En este periodo es común que las inscripciones se realicen en los scriptoria monásticos o bien en talleres ocasionales de carácter rural ${ }^{3}$. En el primer caso, la visigótica será sustituida por

\footnotetext{
primero, el día 18 de enero de 1953, Madrid: Real Academia de la Historia. (=M. Gómez Moreno (1953). El concepto). N. RODRÍGUEZ SUÁREZ (2012). "Un repaso a través de los conceptos de epigrafía e inscripción". Documenta \& Instrumenta, 10, 29-36. (=N. RODRÍGUEZ SUÁREZ (2012). "Un repaso").

${ }^{2}$ V. DEBIAIS (2009). Messages de Pierre. La lectura des inscriptions dans la communication médiévale, Turnhout: Belgica. (=V. Debiais (2009). Messages).

${ }^{3}$ Ma . E. MARTÍN LÓPEZ (1999). "La escritura publicitaria en la Península Ibérica. Siglo XV“. En Ch. Steininger, W. Koch. Inschrift und material Inschrift und Buchschrift. Fachtagung für mit-
} 
la escritura carolina en los primeros años del siglo XII, mientras que en los talleres rurales la tradición visigótica perdurará mucho más tiempo.

El único ejemplo visigótico con el que contamos en la provincia de Salamanca, localizado en la ermita de San Miguel en Zamayón, aparece tan deteriorado- apenas si podemos leer un "[...n]ienior[...]" o "[ ...al]ienior[...]"- que no nos permite realizar más que un análisis somero de su alfabeto, sin poder incidir en otros rasgos como las abreviaturas, los nexos u otros recursos gráficos. Atendiendo a este aspecto podríamos situar su cronología entre los siglos X y XI. Sin embargo, no hay que perder de vista lo expuesto anteriormente. Se trata de una inscripción realizada por un rogatario ocasional, sin cultura urbana. La inscripción carece de impaginatio y su escasa calidad gráfica y técnica nos indica que estamos ante un epígrafe de "cultura rural". Por todo ello, cabría la posibilidad de que esta pieza se acercara incluso más al siglo XII.

El origen de la escritura visigótica, como sabemos, está formado por caracteres mayúsculos con origen en la capital clásica y en la escritura uncial, que en el periodo visigodo van adoptando formas peculiares o propias. Así pues, el alfabeto está compuesto por letras capitales y unciales a las que debemos añadir las minúsculas agrandadas, peculiaridad gráfica de esta escritura ${ }^{4}$.

Entre las letras típicas, que nos ayudan a identificar una inscripción como visigótica, destacan: la $\mathrm{A}$ sin trazo horizontal, la $\mathrm{M}$ cuadrada con los trazos 1 y 4 convergentes hacia arriba o uncial curva, la $\mathrm{O}$ romboidal, la $\mathrm{N}$ con el segundo trazo oblicuo pero casi horizontal, la $\mathrm{R}$ con un tercer trazo rectilíneo, la $\mathrm{S}$ alargada y con las curvas poco desarrolladas, la $\mathrm{T}$ con bucle o con giro hacia arriba y la $\mathrm{Y}$ o la Q minúsculas agrandadas.

La tabla I permite comprobar cómo, efectivamente, aparecen las formas típicas de este tipo de escritura en esta inscripción salmantina. Así, observamos la $\mathrm{N}$ con el trazo central casi horizontal, una $\mathrm{R}$ cuyo último trazo es más corto y tiende a la derecha, o una $\mathrm{O}$ que aquí, quizás por la torpeza del rogatario, se asemeja más a una forma pisciforme invertida que a un rombo.

Este ejemplo presenta ya uno de los rasgos distintivos de la provincia de Salamanca, la presencia tardía de una escritura publicitaria en la zona. La actual

telatterliche und neuzeitliche epigraphik. Ingolstadt 1997, München 1999, pp. 191-206. (=Ma . E. MARTÍN LÓPEZ (1999). "La escritura).

${ }^{4}$ Para un estudio más detallado de la escritura visigótica publicitaria cf. V. GARCÍA LOBO (1999). "La escritura publicitaria en la Península Ibérica. Siglos X-XIII". En Ch. Steininger, W. Koch, Inschrift und material Inschrift und Buchschrift. Fachtagung für mittelalterliche und neuzeitliche Epigraphik Ingolstadt 1997, München:Taschenbuch , pp. 155-166. (=V. GARCÍA LOBO (1999). "La escritura"). 
provincia de Salamanca tenía una gran relevancia en época romana, cuando aparece formando parte de la Lusitania. Era un importante centro de intercambio de todo tipo de productos, al pasar por ella una de los vía romanas más importantes, la vía de la plata. De esta época se conserva un interesante conjunto de inscripciones que se recogen en el C.L.I. ${ }^{5}$ y más recientemente en dos obras, Corpus de inscripciones romanas de la provincia de Salamanca ${ }^{6}$ y Epigrafía de época romana de la provincia de Salamanca?.

$\mathrm{Al}$ adentrarnos en la Edad Media, la situación política del territorio hispánico hace que los datos históricos de este territorio se nos desdibujen, pues se convierte en zona de repoblación y de continuas luchas ${ }^{8}$. Este hecho explica la carencia de inscripciones durante esta primera etapa de la Edad Media. Un único ejemplo que aparece reaprovechado en el muro oeste de la iglesia, colocado de lado y cortado por ambos lados. Esto nos indica que el interés del mensaje epigráfico se había perdido, no así el de la materia prima.

${ }^{5}$ A. HÜBNER (1869). Inscriptiones Hispaniae Latinae, vol. II, Berlín. (= A. HÜBNER (1869). Inscriptiones)

${ }^{6}$ A. ALONSO ÁVILA y S. CRESPO ORTIZ DE ZARATE (1999). Corpus de inscripciones romanas de la provincia de Salamanca: Fuentes epigráficas para la historia social de la Hispania Romana, Valladolid: A. Alonso, S. Crespo. (= A. Alonso Ávila y S. Crespo Ortiz de Zarate (1999). Corpus).

${ }^{7}$ L. HERNÁNDEZ GUERRA (2001). Epigrafía de época romana en la provincia de Salamanca, Valladolid: Centro Buendía. Universidad de Valladolid. (= L. Hernández Guerra (2001). Epigrafía).

${ }^{8}$ L. M. VILLAR GARCÍA (1986). La Extremadura Castellano-Leonesa, guerreros, clérigos y campesinos (711-1250), Valladolid: Junta de Castilla y León, p. 43 (=L. M. VILLAR GARCÍA (1986). La Extremadura) indica que "Al iniciarse la invasión musulmana de la Península Ibérica en el año 711, comenzaba un largo periodo, de casi cuatrocientos años, del que conservamos muy pocas noticias relativas a los habitantes que poblaban el territorio situado entre el Duero y el Sistema Central. A fines del siglo IX las crónicas astures, al relatar las campañas de Alfonso I (739757), incluyen entre las ciudades conquistadas por él a los musulmanes a Ledesma, Salamanca, Ávila, Segovia u Sepúlveda". 
Tabla 1. Alfabetos en escritura visigótica. Elaboración propia.

\section{Escritura Visigótica}

\begin{tabular}{|c|c|c|}
\hline & Grafía visigótica & Grafía perfilada por la autora \\
\hline \multicolumn{3}{|l|}{$A$} \\
\hline \multicolumn{3}{|c|}{$B$} \\
\hline \multicolumn{3}{|c|}{ C } \\
\hline \multicolumn{3}{|c|}{$\mathrm{D}$} \\
\hline \multicolumn{3}{|r|}{ 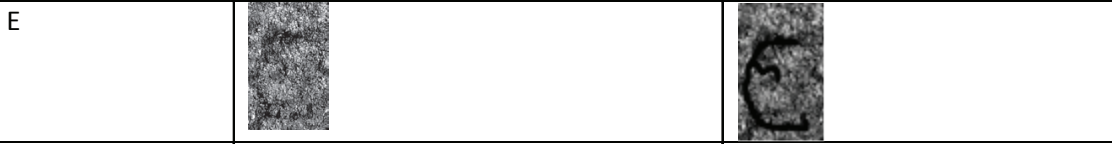 } \\
\hline \multicolumn{3}{|l|}{$\mathrm{F}$} \\
\hline \multicolumn{3}{|l|}{ G } \\
\hline \multicolumn{3}{|l|}{$\mathrm{H}$} \\
\hline \multicolumn{3}{|r|}{ Who } \\
\hline \multicolumn{3}{|l|}{ K } \\
\hline L & (1) & 1 \\
\hline \multicolumn{3}{|c|}{$M$} \\
\hline \multicolumn{3}{|c|}{$N$} \\
\hline \multicolumn{3}{|c|}{0} \\
\hline \multicolumn{3}{|l|}{$P$} \\
\hline \multicolumn{3}{|c|}{$Q$} \\
\hline \multicolumn{3}{|l|}{$R$} \\
\hline \multicolumn{3}{|l|}{$\mathrm{S}$} \\
\hline \multicolumn{3}{|c|}{$\mathrm{T}$} \\
\hline \multicolumn{3}{|c|}{$\mathrm{V}$} \\
\hline \multicolumn{3}{|l|}{$x$} \\
\hline \multicolumn{3}{|l|}{$Y$} \\
\hline Z & & \\
\hline
\end{tabular}




\section{INSCRIPCIONES CAROLINAS}

La escritura carolina publicitaria será la escritura por excelencia en el siglo XII en la mitad norte de la Península ${ }^{9}$. Al igual que sucede con la escritura ordinaria, su introducción se produce de una manera paulatina, dependiendo de las zonas y las influencias exteriores que esas localizaciones recibieron. Generalmente, se producía una etapa de transición, en la que todavía se pueden apreciar rasgos de la escritura anterior, siempre que el rogatario no sea un foráneo habituado ya a escribir en la nueva grafía. La presencia de estos arcaísmos gráficos en los mensajes publicitarios nos indican las fechas de introducción de la carolina en las distintas zonas geográficas.

En el caso de Salamanca, cuatro de las doce inscripciones carolinas que se conservan mantienen aún una fuerte reminiscencia de la escritura visigótica. Son el Epitaphium sepulcrale de María García y su hijo Miguel Juanes, localizado en el convento de Santa María de la Vega ${ }^{10}$, el Monumentum aedificationis de la iglesia de Nuestra Señora del Rosario, en Cerralbo ${ }^{11}$ y los Ephitaphia necrologi$c a$ de Justo ${ }^{12}$ y de Román ${ }^{13}$, ambos en la catedral vieja de Salamanca. A pesar de que datan de 1174, siglo XII, 1177 y 1192 respectivamente, se observan unas O aún muy romboidales, la $\mathrm{E}$ y la $\mathrm{R}$ con los módulos muy alargados, la $\mathrm{X}$ de cuatro trazos y la presencia de una $\mathrm{N}$ cuyo trazo central no alcanza los extremos de los verticales. La presencia de estos rasgos en una cronología tan tardía nos está indicando que, la escritura carolina llega a Salamanca con cierto retraso con respecto a otras zonas más al norte y al este. Si relacionamos estas inscripciones con las de la cercana Zamora, observamos que allí el primer ejemplo en letra carolina data de 1137 y que anteriormente aparecen inscripciones visigóticas con una fuerte influencia carolina ${ }^{14}$. Quizás el fenómeno salmantino haya que ponerlo en relación con lo que está sucediendo en Portugal, donde los primeros ejemplos de grafía carolina se sitúan en los primeros años del siglo XIII ${ }^{15}$.

\footnotetext{
${ }^{9}$ Sobre las particularidades de la letra carolina cf. V. GARCÍA LOBO (1999). “La escritura”, pp. 167-175.

${ }^{10}$ Maria Garcia et filius eius Micael Johanes obierunt, quorum corpora hic requiescunt. Era millesima ducentesima decima segunda, decimo octavo kalendas maii.

${ }^{11}$ [Aedificatum] fuit hoc templum in die tertia nonas iunii

${ }^{12}$ Era millesima ducentesima decima quinta obiit Iustus concanonicus

${ }^{13}$ Quarto nonas marcii obiit famulus dei Romanus era millesima ducentesima trigesima.

${ }^{14}$ M. GUTIÉRREZ ÁLVAREZ (1999). Corpus Inscriptionum Hispaniae Mediaevalium. Zamora. Estudio, I/2, Turnhout-León: Brepols. (= M. GUTIÉRREZ ÁLVAREZ (1999). Corpus).
}

${ }^{15}$ M. J. BARROCA. (2000). Epigrafia medieval portuguesa (862-1422), vol I, Oporto: Fundaçao Calouste Gulbenkian, p. 154 (=M. J. BARROCA. (2000). Epigrafia). 
Indicamos ya que la provincia de Salamanca cuenta con doce inscripciones en letra carolina ${ }^{16}$. Además de los epígrafes ya mencionados encontramos: el Epitaphium sepulcrale de los jóvenes hermanos Martín y Eneco, los Funera de cierta persona cuyo nombre acaba en mercha y que se localiza en la catedral vieja de Salamanca, situada en la panda este del claustro, en un sillar sumamente deteriorado ${ }^{17}$, el del canónigo Martín ${ }^{18}$, y uno indeterminado ${ }^{19}$, ambos reutilizados en el claustro de la catedral vieja de Salamanca, en el muro norte; las Intitulationes necrologicas del prior Bruno, el maestro Iordan, María y Otmaro; la Suscriptio del escultor Nicolás, en Almenara de Tormes ${ }^{20} \mathrm{y}$ ciertas inscripciones que por su deterioro no podemos adscribir a ninguna tipología concreta y que se localizan en la panda este del claustro de la catedral vieja de Salamanca ${ }^{21}$. Desgraciadamente, sólo una inscripción, plenamente carolina, conserva la data, el resto carece de ella. Un menor número de ejemplos dificulta el poder hablar fehacientemente del momento en el que la escritura carolina se asentó definitivamente en la provincia o de si ésta perduró en el tiempo más allá del siglo XII. Pero la presencia de los arcaísmos visigóticos en fechas tan tardías y la cronología retardataria $1192^{22}$ en el único ejemplo datado enteramente carolino, es indicio suficiente para retrasar a finales del siglo XII estas otras inscripciones carolinas carentes de data. Hecho éste que concuerda con la localización documental de ciertos personajes a los que se alude en algunos de esos epígrafes, sin fórmula de datación y que se pueden situar a finales de esa centuria ${ }^{23}$.

\footnotetext{
${ }^{16}$ Sobre las particularidades de la letra carolina cf. V. GARCÍA LOBO. (1999). "La escritura”, pp. 167-175.

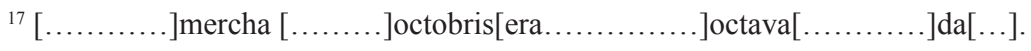

${ }^{18}[\ldots]$ Kardinalis $[\ldots] \mathrm{o}$ Martine redis[...o $] \mathrm{s}$ humi celo men[s...]

${ }^{19}$ Carnis que sopore, te deo vigilas.

${ }^{20} \mathrm{Nicholau}[\mathrm{s}]$ me fecit.

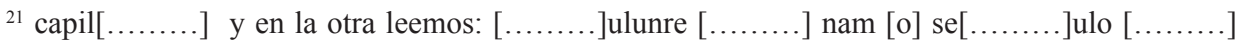
vens.

${ }^{22}$ Epitaphium sepulcrale de los jóvenes Marín y Eneco.

${ }^{23}$ Sobre el funus del canonigo Martín convienen indicar que este personaje es el cardenal Martín al que aluden algunos autores. Según G. GONZÁLEZ DÁVILA (1606). Historia de las antigüedades de la ciudad de Salamanca: vida de sus obispos y cosas sucedidas en su tiempo, Salamanca: Artus Taberniel. (ed. 1994), p. 196 (=G. GONZÁLEZ DÁVILA (1606). Historia) es el obispo anterior a Gonzalo. Por tanto, anterior al siglo XIII. Q. ALDEA, T. MARÍN MARTÍNEZ, y J. VIVES (1975). Diccionario de historia eclesiástica de España, Madrid: C.S.I.C., p. 2143, (=Q. ALDEA, T. MARÍN MARTÍNEZ, y J. VIVES (1975). Diccionario) cita en la sede salmantina a Martín, entre 1229 y 1245, A. ALONSO ÁVILA y S. CRESPO ORTIZ DE ZARATE (1999). Corpus de inscripciones romanas de la provincia de Salamanca: Fuentes epigráficas para la historia social de la Hispania Romana, Valladolid: A. Alonso, S. Crespo. , p. 263 (=E. Toribio Andrés. (1944). Salamanca)
} 
La escasez de inscripciones en este tipo de escritura, es un rasgo que se pone en conexión con lo que hemos analizado en la escritura visigótica de la zona. La situación geográfica y los avatares históricos acaecidos explican esta particularidad.

Las inscripciones carolinas salmantinas presentan muchas de las características gráficas generales de esta escritura a las que se unen ciertos matices que analizaremos pormenorizadamente a continuación.

En primer lugar, hemos de señalar que esta escritura se caracteriza por presentar un módulo menos alargado que el visigótico, que va buscando la relación modular, alto partido por ancho, de 1 que caracterizará la escritura gótica del siglo XIII, lo que le da sensación de pesadez al epígrafe.

Los caracteres alfabéticos son mayúsculos, con predominio de los de origen capital; también aparecen los de origen uncial, sin abandonar las minúsculas agrandadas. Como letras típicas destacamos la A que definitivamente incorpora el trazo horizontal, que se acompaña, a su vez, de otro en la parte alta de la letra. Esta forma presenta ciertas variantes, como el empleo del trazo horizontal en forma de $\mathrm{V}$, que vemos en el ejemplo 2 de la tabla; otra en la que el primer y segundo trazo no llegan a converger (ejemplos 1 y 3), o el modelo en el que el trazo horizontal superior es recto o ligeramente curvo (ejemplos 1, 2 y 3). La que recogemos en el ejemplo 4 es particular, pues en Salamanca únicamente aparece en una inscripción. Se trata de la A vuelta en forma de $\mathrm{R}$ invertida que sí abunda en el territorio leonés, por ejemplo. Quizás este rasgo de esa única inscripción nos esté indicando que el rogatario o el epígrafe habían viajado desde la zona norte.

Conviven dos tipos de E, la cuadrada, y la redonda que, como vemos en los ejemplos, pueden llevar trazos superfluos decorativos (ejemplo 4).

La $\mathrm{M}$ de origen uncial, con el primer trazo redondeado y el segundo curvado hacia fuera (ejemplos 2 y 3), comparte espacio con la M capital de trazos externos paralelos (ejemplos 1 y 4) y con otra de formas más redondeadas (ejemplo 4).

\footnotetext{
alarga su obispado hasta 1246. Sin embargo, nosotros pensamos que la palabra Kardenalis, podría traducirse también como canónigo. Así lo vemos, por ejemplo, en Arbas del Puerto, León, donde se utilizó este apelativo para los canónigos.

Sobre la intitulatio necrologica del prior Bruno y sus compañeros decir que en la documentación relacionada con la catedral encontramos referencia a un Brunus prior, que aparece confirmando en tres documentos fechados en: 14, mayo de 1161(A.H.N. Clero, Salamanca, Catedral, Carp.1879, $\mathrm{n}^{\mathrm{o}}$ 8), en 1163, enero, 13 (A.C.S. caj. 6, leg. $3 \mathrm{n}^{\circ}$ 58), y en 1164, agosto, 15 (A.H.N. Clero, Salamanca, catedral, carp. 1879, $\mathrm{n}^{\circ} 10$ ). También se hace referencia al maestro Ihordan en 1185, febrero, 3 (A.C. S. caj. 14, leg. $2 \mathrm{n}^{\circ} 22$ ) y en 1185, octubre, 27 (A.C.S. caj.3, leg.3, $\mathrm{n}^{\mathrm{o}} 12$ ). Respecto a María Pequeña, no la hemos localizado, pero sí a personajes que llevan este apelativo en el siglo XIII. (A.H.N. Clero, Salamanca, Catedral, carp. 1880 n 18 leemos "Iohan Pequeño").
} 
De la misma manera, poco a poco irá perdiendo fuerza la $\mathrm{N}$ con travesaño horizontal visigótica (ejemplos 1), que será sustituida, bien por otra con el travesaño invertido (ejemplo 2), bien por la $\mathrm{N}$ capital y por otra $\mathrm{N}$ con el segundo trazo curvo que termina hacia fuera, lo que la asemeja a una $\mathrm{R}$.

La $\mathrm{O}$ romboidal, desaparece en favor de la $\mathrm{O}$ de riñón, que es la más abundante (ejemplo 2) y en menor medida la $\mathrm{O}$ clásica (ejemplo 3).

En cuanto a la $\mathrm{R}$, el último de sus trazos logrará alcanzar la línea de escritura; aunque al principio es recta, al modo visigótico, poco a poco se irá curvando (ejemplos 2 y 3 ).

La T ha perdido su bucle y junto con la cuadrada, que aparece en algunos ejemplos, la más habitual será la que presente el segundo trazo más o menos curvo (ejemplos 2 y 3 ). En ocasiones a los dos trazos de la T se le añade otro que une el trazo horizontal y el curvo (ejemplo 4).

Por último, es de reseñar también la $\mathrm{V}$ que presenta dos variantes, la capital clásica de dos trazos rectos (ejemplo 2) y otra con el primer trazo curvo y el segundo recto, resultando éste muy reducido (ejemplo 3).

Por lo que se refiere a las abreviaturas, letras sobrepuestas, signos especiales y signos publicitarios se utilizan los tradicionales; el empleo de la línea sobrepuesta para señalar la presencia de palabra abreviada, el signo típico carolino de final en -US, con forma de una gran coma (9); o la presencia de Et con la nota tironiana (7). A este respecto los ejemplos salmantinos presentan como particularidad el reducido empleo de este tipo de elementos. Sólo en dos de las inscripciones se hace uso de ellos, las Intitulationes necrologica del prior Bruno, el maestro Iordan, María y Otmaro, en el claustro de la catedral vieja de Salaman$\mathrm{ca}^{24}$ y el Epitaphium de María García y su hijo, en el convento de Santa María de la Vega ${ }^{25}$.

El uso de los nexos es casi inexistente, algo usual en este tipo de escritura y únicamente cabe llamar la atención sobre una grafía especial que aparece en una de estas inscripciones carolinas. Se trata del nexo de $\mathbf{S}$ y $\mathbf{T}$ tomado de la escritura minúscula ordinaria, que vemos en la palabra magister de nuevo en las Intitulationes necrologicas del prior Bruno, el maestro Iordan, María y Otmaro, en el claustro de la catedral vieja da Salamanca. Este fenómeno nos está indicando que el rogatario de esta inscripción estaba habituado a escribir también en libros y documentos.

\footnotetext{
${ }^{24}$ Brunus prior et magister Iordan, Maria Pequena, Otmaro.

${ }^{25}$ De manera anecdótica en el Epitaphium de Justo en la expresión de la Era (E), en el Epitaphium sepulcrale de los jóvenes Martín y Eneco con un et tironiano.
} 
Imagen 1.Detalle nexo ST en Intitulationes necrológicas del prior Brunus y sus companeros. (Archivo propio).

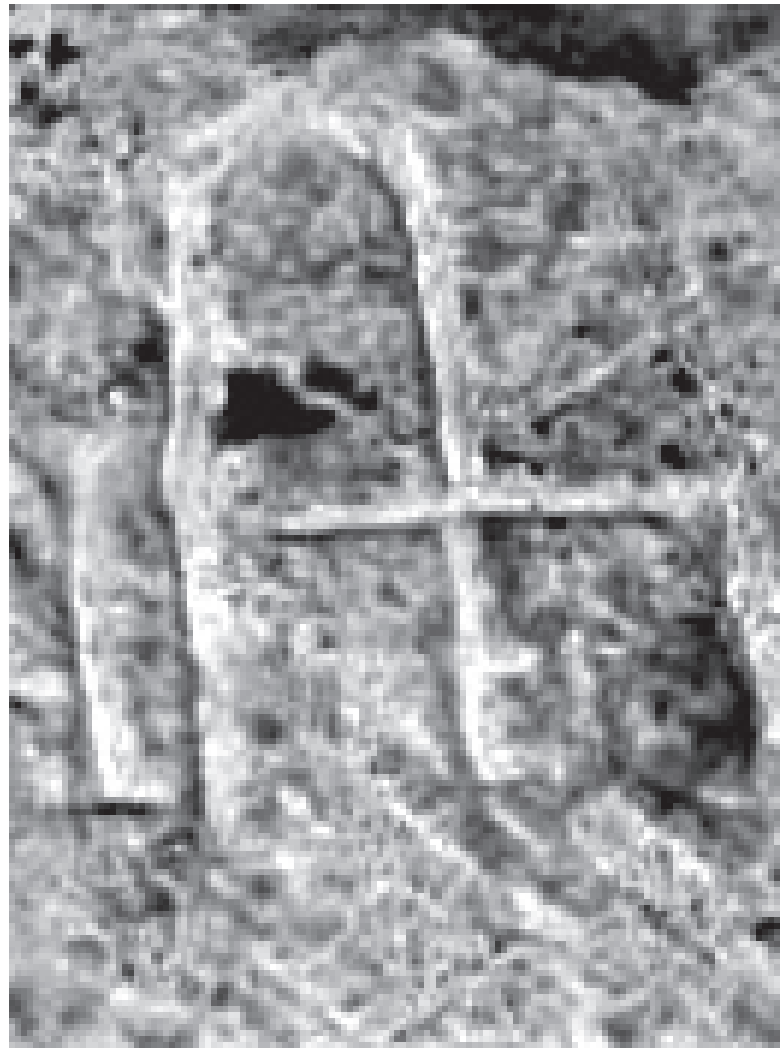


Tabla 2. Alfabetos en escritura carolina. Elaboración propia.

\section{Escritura Carolina}

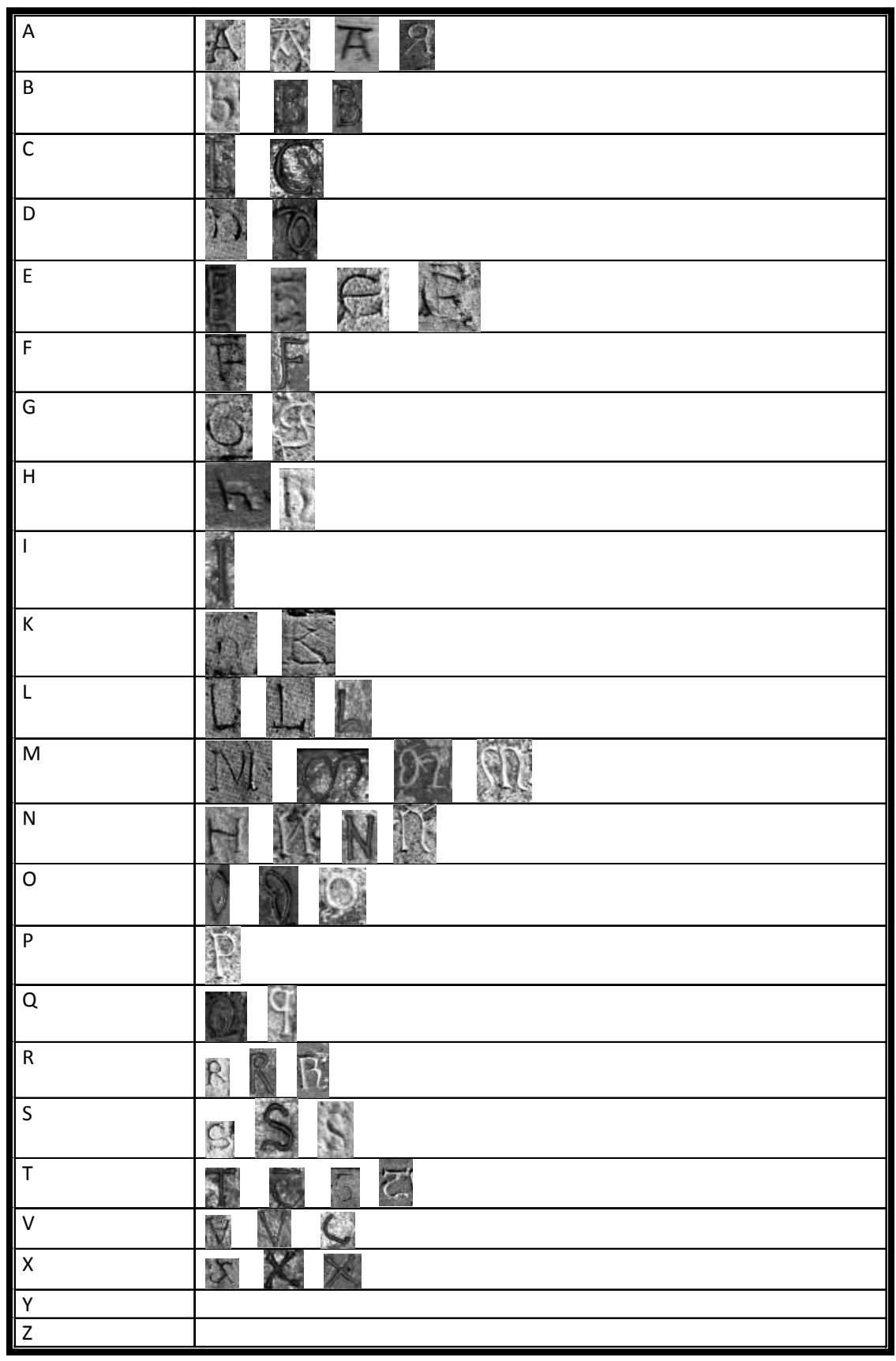




\section{INSCRIPCIONES GÓTICAS}

Como es bien sabido, el ciclo de la escritura gótica es el más largo de las escrituras medievales. Tanto la escritura ordinaria como la publicitaria sufren una profunda evolución a lo largo de los siglos XIII, XIV y XV que, en el caso de las inscripciones, nos permite distinguir entre las del siglo XIII, las del siglo XIV y las del siglo $\mathrm{XV}^{26}$.

Esta clasificación por siglos tiende a generalizar rasgos gráficos para comprender mejor un fenómeno gráfico de características muy concretas y acusadas en cada una de estas cronologías. Ello no quiere decir que esas características no aparezcan o se mantengan entre siglos. Así por ejemplo, las características de la escritura gótica que llamamos "del siglo XIV" pueden apuntar ya a finales del siglo XIII, y la que llamamos "gótica del siglo XV" puede aparecer y de hecho aparecen ya a finales del siglo XIV ${ }^{27}$.

\section{ESCRITURA GÓTICA DEL SIGLO XIII}

Son diecisiete las inscripciones en este tipo de escritura que se localizan en la actual provincia de Salamanca.

Un conjunto de ellas todavía conservan muchos rasgos de la escritura carolina, lo que nos indica que estamos ante epígrafes realizados en una escritura gótica del siglo XIII inicial; aportando así las fechas de introducción de este tipo de escritura en el territorio salmantino y los centros de introducción de la misma.

\footnotetext{
${ }^{26}$ Sobre las inscripciones góticas cf. Ma . E. Martín López y V. García Lobo (Coords), (2010). Las inscripciones góticas. II Coloquio Internacional de Epigrafía medieval. León del 11 al 15 de septiembre 2006, León: Corpus Inscriptionum Hispaniae Mediaevalium. (=. Mª . E. Martín López y V. García Lobo (Coords), (2010). Las inscripciones).

${ }^{27}$ Sobre este proceso de evolución cf. P. Deschamps (1929). Étude sur la paléographie des inscriptions lapidaires de la fin de l'époque mérovingienne aux dernières années du XIII ${ }^{e}$ siècle, Paris. (= P. Deschamps (1929). Étude) ; A. Durán Gudiol (1967). Las inscripciones medievales en la provincia de Huesca: Estudios de la Edad Media de la corona de Aragón, vol. VII, Zaragoza: Escuela de estudios medievales. (= A. Durán Gudiol (1967). Las inscripciones), V. García Lobo (1982). Las inscripciones, V. García Lobo (1999). "La escritura”, pp. 175-183; M. J. Barroca (2000). Epigrafia, pp. 161 y ss; AA.VV. (1999) Deutsche inschriften. Terminologie zur Schriftbeschreibung, Viena: Akademie der Wissenchaften in Wien. (= AA.VV. (1999). Deutsche).
} 
Se trata del Epitaphium necrologicum de Randulphus ${ }^{28}$, el Epitaphium sepulcrale de cierto Aliam ${ }^{29}$, ambos en la catedral vieja de Salamanca y la Consecratio de la iglesia de Santa María de los Caballeros ${ }^{30}$.

Las cronologías de las dos primeras se encuentran muy cercanas en el tiempo, están datadas en 1194 y 1195 respectivamente ${ }^{31}$. Es precisamente la temprana cronología la que ayuda a explicar esas reminiscencias. Además, las dos inscripciones guardan una gran semejanza gráfica que nos invita a pensar en un mismo rogatario, si no fuera por la torpeza de la segunda y el cuidado y esmero de la primera. Sin embargo, creo que se puede hablar de un mismo taller en que trabajan maestro y discípulo.

No resulta extraño que sea la ciudad de Salamanca y la catedral, como centro clave, el lugar elegido para realizar esta renovación gráfica que supuso la nueva escritura gótica.

En el caso de la Consecratio de Santa María de los Caballeros la data ofrecida nos adentra ya en el siglo XIII, 1214. En este caso la presencia de rasgos gráficos retardatarios se explica por las particularidades que presenta el calígrafo, cuya grafía parece torpe y resulta estar poco avezado en la escritura gótica del XIII.

En el otro extremo tenemos las inscripciones del muro oriental de la capilla de San Martín, en la catedral vieja de Salamanca, que ya apunta las características de la llamada "gótica del XIV"32. Esos mismos rasgos se aprecian también en las

\footnotetext{
${ }^{28}$ Sexto idus marcii obiit famulus Dei Randulphus. Era millesima ducentesima trigesima secunda mense die decima martis (sic), Randulphus ab ima parte fugit mundus, quem non quit claudere mundus: terrea nam terris mandant, celica celis. Sol radians titul(um) virtutum, flos sine labe. Solus in occasu miseris est passus eclipsi. Randulphus, plene qui phisit novit utramque mens bene disposuit sermo docuit manus egit huius dicta bonus, melior fuit optimus, ipse et pauperibus moritus vivens sibi celo.

${ }^{29}$ Era millesima ducentesima trigesima tertia, vir pius atque fidus, vir sinplex iustus. In idus septembris moritur Aliamus et hic sepelitur. Terrea terra tegit celo pars celica degit. Utraque, natura servavit sit sua iura.

${ }^{30}$ (Cruz) In nomine domini nostri Ihesu amen. Dedicata fuit ecclesia ista in honore et titulo beate Marie virginis et Sancti Mauricii et de veste beate Mariae et de loco ubi Dominus ieiunavit et de ligno crucis, Domini et de cor[p]oris Christi et dedicavit eam Gundisalvus Salmantinus episcopus sexto [kalendas] maii era (millesima) ducentesima quincuagesima segunda.

${ }^{31}$ Cabe la posibilidad de que las inscripciones se hicieran con posterioridad a la muerte del difunto, aunque la diferencia entre un hecho y el otro, generalmente no se aleja demasiado.

${ }^{32}$ A: Esta obra fiz yo Anton Sanchez de Segovia. Era de mil e trescientos.

B: In ecel Glori(e). Ieremias, Angelus Rafael, Ysayas, Daniel, Angelus Angelus, Angelus Angelus, Angelus domini Angelus, Ana, Ioaquin.
} 
Hortationes de la iglesia de Santibañez ${ }^{33}$ y en la Consecratio de la iglesia de San Juan de los Barbalos ${ }^{34}$. Presentan muchos de los elementos característicos de la gótica del siglo XIV como son: la F que se cierra, la L que incorpora un tercer trazo o la A que recuerda la típica del siglo XIV.

Desgraciadamente, en este caso, aunque dos de las cuatro conservan data, éstas no resultan significativas para ofrecer una cronología del inicio de la sustitución de la escritura gótica del siglo XIII. La consagración de San Juan de los Bardalos, se sitúa en 1201, pero, sin duda, estamos ante un original tardío. Por su parte, la data de la inscripción de las pinturas murales del muro oriental de la capilla de San Martín, 1262, ha resultado siempre controvertida, tanto para la escritura como para las pinturas que la acompañan, que resultan de una calidad muy superior a las que se hacían por esa fecha ${ }^{35}$. Quizás la explicación esté, de nuevo, en la presencia de un original tardío.

El análisis de los diecisiete ejemplos con los que contamos nos permite presentar un panorama general de los rasgos alfabéticos de la escritura del siglo XIII en esta zona.

La escritura gótica del siglo XIII se caracteriza por presentar unas formas alfabéticas poco angulosas, tendiendo a la redondez de los trazos, con un módulo con letras aproximadamente tan altas como anchas, y por la tendencia de las letras a cerrarse sobre si mismas.

Destacar la aparición de un tipo de A cuyo segundo trazo es recto, mientras que el primero tiende a la izquierda (ejemplos 2,5 y 7) que irá ganando camino hasta que en el siglo XIV se convierte en la A más habitual. El gusto por las formas redondeadas hace que se emplee la $\mathrm{E}$ minúscula agrandada (ejemplo 2)

C: Esta capiela es de Sant Martin confesor.

D: [Maria mater Dei .............. O O vos omnes qui transitis per viam atendite et [videte si est dolor similis] sic[ut dolor meus] .

${ }^{33}$ Quisquis amat Christum mundum non diligit istum set quasi fetorem spernit illius amorem y en la otra leemos: O diues diues non omni tempore uiues fac bene dvm uivis post mortem vivere si vis

${ }^{34}$ [In nomi]ne domini nostri Ihesu Christi. Dedicata fuit ecclesia in honore beati Ihoanis Babtiste et aliorum plurimorum sanctorum et dedicavit eam Gondisalvus Fernandiz s[al]amantinus episcopus, et fecerunt eam dedicare frater Iohanes Ovequiz, comendator eiusdem domus et Pet[r]us Pe[la]gii del Pozo et uxor eius Maria de [A]g[ui]lar era millesima et ducentesima et tregesima nona, quinto decimo kalendas maii.

${ }^{35}$ Los distintos especialistas en la pintura gótica ofrecieron distintas explicaciones que se recogen en: F. GUTIÉRREZ BAÑOS (2000). Pinturas de estilo gótico lineal en Castilla y León En: XIII Congreso Nacional de Historia del Arte. Ante el nuevo milenio: raices culturales, proyección y actualidad del arte español. Granada 31 de octubre- 3 de noviembre, vol II, pp. 1102-1105. Granada: Universidad de Granada. (=F. Gutiérrez Baños (2000). Pinturas). 
junto con la E redonda que se va cerrando. Lo mismo sucederá con la G cuyo bucle casi alcanza la parte alta de la letra (ejemplo 1, 3, 4 y 5). También aparece como novedad una $\mathrm{L}$ con el segundo trazo curvo (ejemplo 3). La P aumenta su "panza" que aumenta el bucle hasta alcanzar casi la parte baja del primer trazo, en esa búsqueda de la redondez. (ejemplo 3). En esta letra, además, se incorpora una grafía nueva abierta por arriba (ejemplo 2). Otras letras como la S, la T o la $\mathrm{V}$ acaban cerrándose casi por completo.

Las abreviaturas siguen un comportamiento análogo a la época anterior, se utilizan los tres tipos tradicionales. Como signo general de abreviación sigue empleándose la línea sobrepuesta. En algunas inscripciones esa línea horizontal se sustituye por un semiyugo con la misma función. Así lo vemos, por ejemplo, en el Epitaphium de Justa Pérez de Colimbra en la catedral vieja de Salamanca ${ }^{36}$ o en el Doña Bona, en la iglesia de San Martín de la misma ciudad ${ }^{37}$. Esta última inscripción presenta otra peculiaridad. En ella el semiyugo comparte espacio con una especie de V casi horizontal, que tiene la misma función. Esta ambivalencia de signos para un mismo carácter se aprecia también en la Consecratio de Santa María de los Caballeros en Salamanca, donde vemos ( $\overline{\mathrm{B}} \mathrm{E})$ para beate con una sencilla línea horizontal, mientras que en la palabra dominus (DÑS) utiliza el semiyugo ${ }^{38}$.

El signo especial de final en -US gana en dimensiones y tiende a colocarse en la caja de escritura, ocupando el espacio de una letra, como puede apreciarse en el Epitaphium sepulcrale de la conversa Inés en el convento de Santa María de la Vega ${ }^{39}$ o en el de Pedro Pérez en la catedral vieja de Salamanca ${ }^{40}$.

\footnotetext{
${ }^{36}$ Noveno kalendas octobris obiit Iusta Petri colinbriensis, uxor magistri Dominici de Ingeniis . Era millesima ducentesima quincuagesima.

${ }^{37}$ Simplex, veridica, pia, provida, icris amica; conditur hic bona per sua facta bona; hic iacet domina Bona, uxor Iohanis Bernardi, et obiit septimo ydus februarii era millesima tricentesima decima sexta. Cuius anima requiescat in pace.

${ }^{38}$ (Cruz) In nomine domini nostri Ihesu amen. Dedicata fuit ecclesia ista in honore et titulo beate Marie virginis et Sancti Mauricii et de veste beate Mariae et de loco ubi Dominus ieiunavit et de ligno crucis, Domini et de cor[p]oris Christi et dedicavit eam Gundisalvus Salmantinus episcopus sexto [kalendas] maii era (millesima) ducentesima quincuagesima segunda.

${ }^{39}$ (Cruz) Hic requiescit famula Dei donna Ignes, conversa huius ecclesie, que obiit septimo kalendas septembris era millesima ducentesima sexagesima quarta.

${ }^{40}$ Hic presul Petrus Petri iacet. Alma Maria eius sis anime dux, via, virgo pia. Egregius, socius humilis, pius atque benignus, vir fuit et paciens, prelati nomine dignus, omnibus hospicium fuit, hic gaudens dare donum cleri presidium, promtus ad omne bonum hic expendebat dans cunctis quicquid habebat hic dare non renuit, mens dare tota fuit presule de Petro breviter volo dicere metro quem tegit hec petra per mea scribo metra mors fuit ipsius multis lacrimabile funus huic. Miserere, Deus qui regnas trinus et unus.
} 
Otras de las formas abreviadas que se localizan en estas inscripciones es el signo especial de PER con una $\mathrm{P}$ cuyo trazo vertical es atravesado por otra línea horizontal. Éste se emplea en el Epitaphium de doña Bona "per sua" $\underline{\mathrm{P}} \mathrm{SUA}$, y en una de las Hortatio de la iglesia de san Justo en Santibáñez, que lo emplea en la palabra SPNIT (spernit).

Lo mismo sucede con el signo de ur, representado como una especie de z sobre la línea de escritura, que sólo lo encontramos en el Epitaphium sepulcrale de Aliam, en la palabra sepelitur (SEPELIT²).

Por último, la única inscripción que abrevia el final um es la Consecratio de la iglesia de San Juan de los Barbalos ${ }^{41}$ y lo hace de una manera muy peculiar, utilizando para ello una especie de tridente.

El empleo de letras sobrepuestas, recursos publicitarios o de et con la nota tironiana se reduce hasta convertirse en algo meramente anecdótico o incluso inexistente como en el caso de los cruzamientos.

\footnotetext{
${ }^{41}$ [In nomi]ne domini nostri Ihesu Christi. Dedicata fuit ecclesia in honore beati Ihoanis Babtiste et aliorum plurimorum sanctorum et dedicavit eam Gondisalvus Fernandiz s[al]amantinus episcopus, et fecerunt eam dedicare frater Iohanes Ovequiz, comendator eiusdem domus et Pet[r]us Pe[la]gii del Pozo et uxor eius Maria de [A]g[ui]lar era millesima et ducentesima et tregesima nona, quinto decimo kalendas maii.
} 
Tabla 3. Alfabetos en escritura gótica del siglo XIII. Elaboración propia.

\section{Escritura gótica del XIII.}

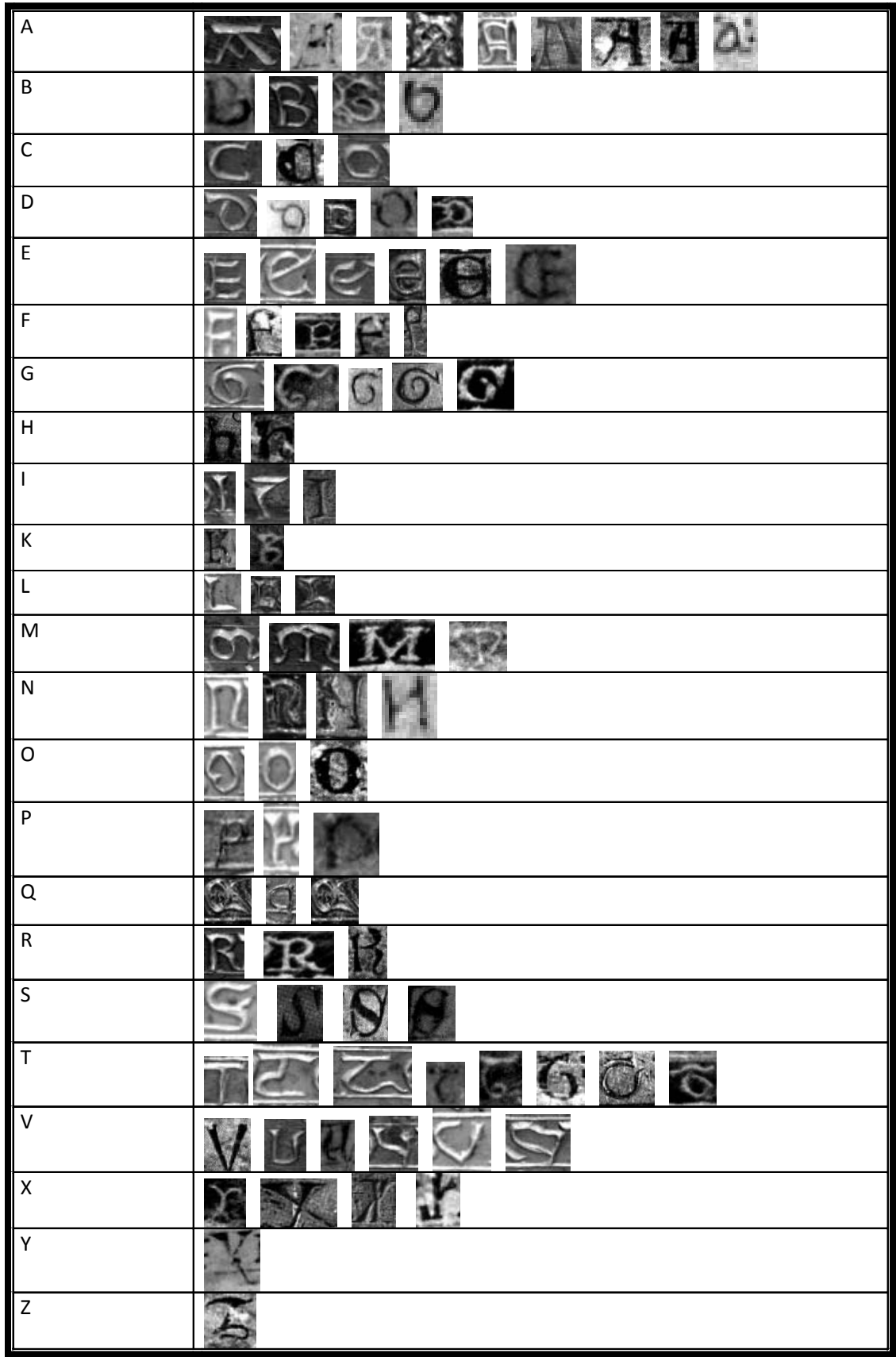




\section{ESCRITURAS GÓTICAS DEL SIGLO XIV.}

La letra gótica del siglo XIV puede considerarse una continuación evolutiva de las características del siglo XIII, aunque con un cambio importante que la vuelve inconfundible. Ahora el módulo se alarga, siendo la relación modular -alto partido por ancho- de 2 aproximadamente. Este rasgo parece deberse a la necesidad de plasmar unos textos cada vez más prolijos en un campo proporcionalmente reducido ${ }^{42}$.

Contamos con treinta y siete ejemplos en letra gótica mayúscula del siglo XIV. En tres de ellos la tempranísima data evidencia claramente que el tiempo trascurrido entre el hecho que se refleja y la plasmación del mismo es muy amplia, lo cual nos hace pensar que se trata de copias epigráficas o bien de originales tardíos $^{43}$. Así lo vemos en los Epitaphia sepulcralia de Pedro Bernardo del Carpio fechados en 1075, ambos en la iglesia de San Martín de Salamanca, una pintada y otra incisa ${ }^{44}$. También en el de Gómez de Anaya de 1190, en la catedral vieja de Salamanca ${ }^{45}$. Se trata de recuperar la memoria de estos personajes, en ocasiones varios siglos después de su muerte. Cabe la posibilidad de que hubiese un Epitaphium anterior y que en el siglo XIV fuera necesario hacer una copia, tal vez por el deterioro que sufrían los originales. Aunque también es posible de que se trate de originales tardíos, que intentan recuperar la memoria de ciertos personajes relevantes para Salamanca. Así, en el caso de Pedro Bernardo del Carpio, este no era otro que el descendiente directo del famoso héroe Bernardo del Carpio, mientras que Gómez de Anaya, es el primero de esta larga estirpe de caballeros salmantinos.

El Mandatum indulgentiae que se localiza en la catedral vieja de Salaman$\mathrm{ca}^{46}$, por su parte, es una copia-reinterpretación de varios documentos pontificios

\footnotetext{
${ }^{42}$ Sobre las particularidades de esta letra cf. V. GARCÍA LOBO (1999). "La escritura”, p. 183.

${ }^{43}$ Sobre las copias epigráficas cf. V. GARCÍA LOBO y Ma. E. MARTÍN LÓPEZ (1995). De Epigrafia Medieval. Introducción y Álbum. León: Universidad de León, p. 42. (=V. GARCÍA LOBO y Ma. E. MARTÍN LÓPEZ (1995). De Epigrafia).

${ }^{44}$ [Hi]c iacet Pe[tru]s Ber[nardi] del C[ar]pio [filius] Ioanis Be[r]n[ardi] del Ca[rpio][qui obit], una y (Cruz) Hic iacet Petrus Bernardi del Carpio, filius Ioanis Bernardi del Carpio, qui obit vigesimoquinto dies iuniy ano domini millesimo septuagesimo quinto, cuyus anima requiecit in pace, la otra.

${ }^{45}$ Aqui iaz don Gomez de Annaya, que fino veinticuatro dias de dezembrio, en la era de mil et doscientos et veintiocho annos.

${ }^{46}$ El papa Clemente quarto da a los que vinieren a las festas de sancta Maria con su ochavario, cada dia cien dias que fazen veintidos quarentenas e media. El papa Nicholao quarto, de la orden de los frades menores, da a todos los que vinieren a las festas de sancta Maria con su cruz ochavario, un anno e quarenta dias, que fazen cada festa con su ochavario, noventa e una quarentena e catorce dias. Item, a los que vinieren a esta eglesia qualquier dia maior, mientre en las festas de sancta Ma-
} 
concedidos a la catedral. Es evidente que en un cierto momento, con posterioridad a la concesión, se hizo necesario dar publicidad a estos documentos, para que los fieles siguiesen acudiendo y haciendo donativos a la fábrica de la catedral. Esta inscripción, sin fórmula de datación, se data en torno a 1289, pues es la fecha de las bulas que está reinterpretando. Puede parecer una fecha temprana y quizás haya que posponerla algo en el tiempo. Pero no hay que esperar demasiado para encontrar otro ejemplo de escritura gótica del siglo XIV en la propia catedral, se trata del Epitaphium sepulcrale de cierto personaje apellidado Pérez ${ }^{47}$, de 1293. En 1303 en la misma localización, el posible Funus de Diego Fernández, deán de Salamanca, que fino entrono a 1303, según la documentación ${ }^{48}$. A partir de dicha fecha los ejemplos se suceden.

Así pues, atendiendo a estos datos, podemos afirmar que al arrancar el siglo XIV, la escritura gótica del siglo XIV aparece perfectamente implantada, en Salamanca. Y que su introducción podría adelantarse a finales del siglo XIII.

Como características generales de los alfabetos de esta escritura salmantina hemos de destacar que la tendencia de las letras a cerrarse sobre sí mismas es un hecho evidente, especialmente en el caso de la $\mathrm{C}$ y la $\mathrm{E}$, que unen sus extremos o incorporan un trazo vertical que los une, formando casi una $\mathrm{O}$ (ejemplos 3 y 4). Hacia la misma forma tienden otras letras como la $\mathrm{G}$ la $\mathrm{T}$ o la $\mathrm{D}$ que cierran sus bucles o letras como la $\mathrm{H}$, la $\mathrm{N}$ o la $\mathrm{M}$ que tienden a unirse en la parte inferior, optando sus formas unciales. La $\mathrm{E}$ es fundamentalmente de forma redonda, de manera que la cuadrada prácticamente desaparece (ejemplos 1, 2, y 3). Algo similar ocurre con la F que une mediante otra línea los trazos horizontales (ejemplos 2,3 y 5). La letra más característica es la $\mathrm{L}$ que incorpora un tercer trazo para cerrarse (ejemplos 2 y 3 ). Por último, en la $\mathrm{P}$ o en la $\mathrm{Q}$, el cuerpo se desarrolla en detrimento de los caídos. También será típica la A con visera a la izquierda y con el trazo de la derecha recto. En ocasiones, esta A alarga, además, el trazo de la izquierda formando un caído por debajo de la línea de escritura (ejemplos 2, 3 y 4).

El número de abreviaturas disminuye considerablemente. Hay textos en los que no se utiliza este recurso; en otros simplemente lo hacen en una o dos palabras.

ria, e ficieren aiudorio a la obra o a la luminaria an perdones de quatro arcobispos e de veintinueve obispos, que dan cada uno dellos quarenta dias de perdon.

${ }^{47}$ Aqui iaz $[\ldots$...e $]$ rez, $[\ldots$ o...n... $]$ de $[$... que fino] en la era mil et trescientos et treinta y un annos.

${ }^{48}$ A. H. N., Clero, carp. 1886, n. 19. [........ Did[a]co s[ach.........]r s[ic]il[ [............... $]$ iam

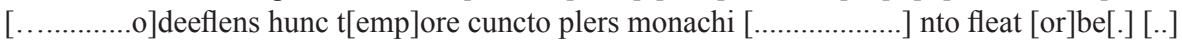

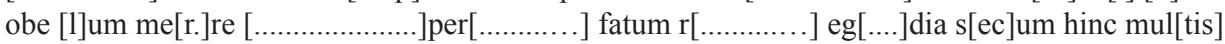

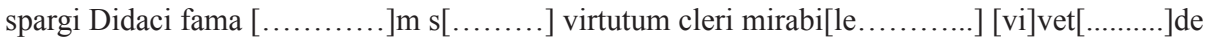
honorum [es]se puto $\mathrm{m}[$ ir....................... pro[bita]tis possit f[erre] virum sibi $\mathrm{p}[\mathrm{a}] \mathrm{s}[\ldots \ldots \ldots \ldots \ldots . .]$. pietat[is]. 
Como signos de abreviación más habitual encontramos la línea horizontal sobrepuesta, bien con valor general, bien para abreviar nasal o E. Continua el empleo de los tres signos tradicionales.

El recurso de las letras sobrepuestas disminuye hasta casi desparecer y son muy escasos los ejemplos.

También encontramos el signo especial de per $\underline{\mathrm{P}}$, en el Mandatum indulgentiae de la catedral vieja de Salamanca, dos veces, y en las Explanationes y Roborationes de la capilla de San Martín, dentro de esta misma catedral.

El signo de -US, habitual en la etapa anterior, únicamente aparece en las Explanationes de la capilla de San Martín, de la catedral vieja de Salamanca.

La nota tironiana para et sólo se recoge en el Epitaphium de Benito Sánchez, en la catedral de Ciudad Rodrigo.

En cuanto a los recursos publicitarios hemos de señalar que no se utilizan en la escritura salmantina del siglo XIV. 
Tabla 4. Alfabetos en escritura gótica del siglo XIV. Elaboración propia.

\section{Escritura Gótica del S. XIV}

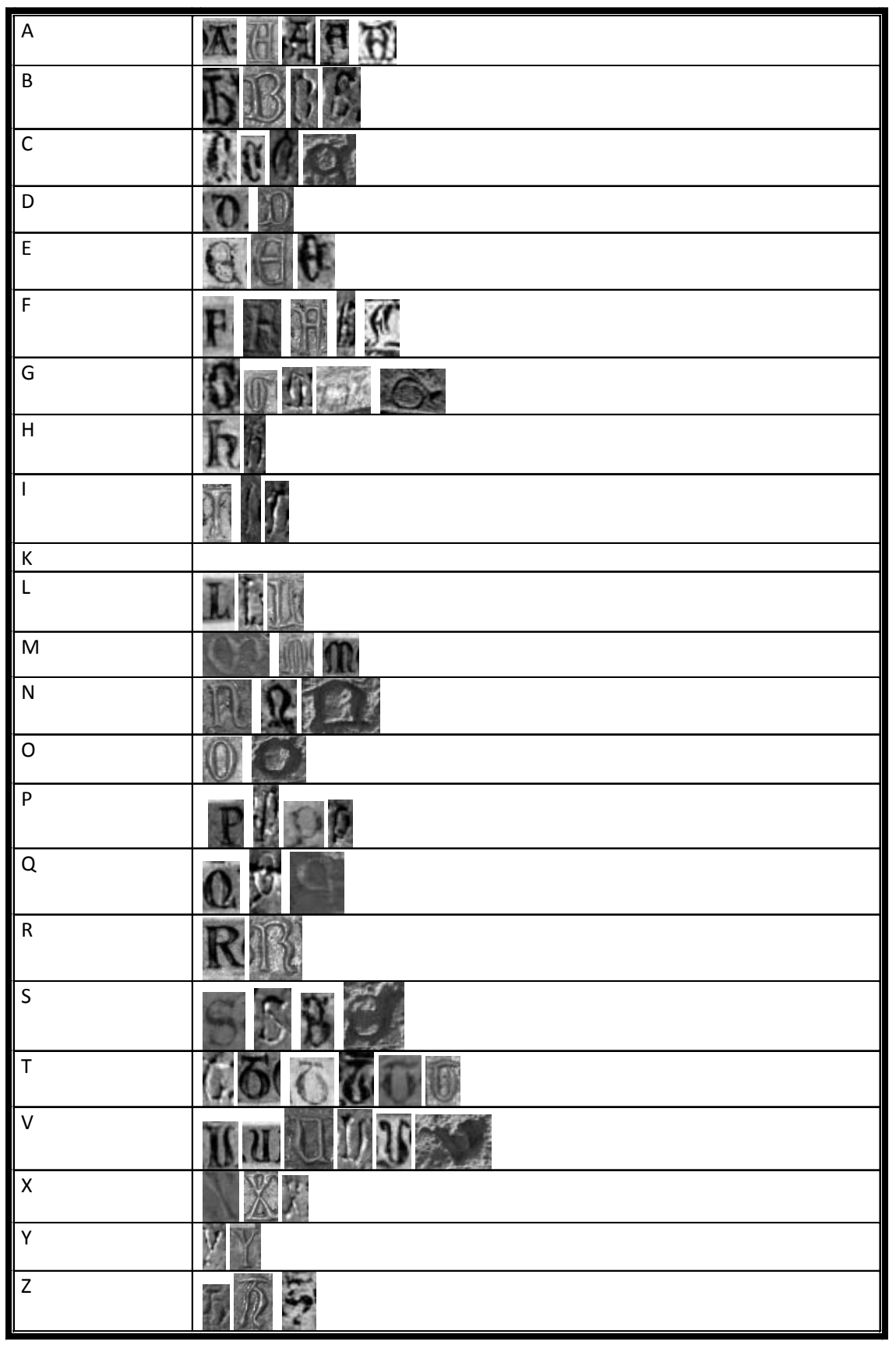




\section{ESCRITURAS GÓTICAS DEL SIGLO XV.}

En el siglo XV la escritura publicitaria de las inscripciones -la de los códices, antes- experimenta un cambio radical: se abandona la letra mayúscula y se adopta definitivamente la minúscula que ya había aparecido en el siglo XIV. La introducción de esta grafía minúscula parece estar relacionada con el mundo del códice y el prestigio que la letra gótica caligráfica había adquirido ${ }^{49}$. La profesora Martín López lo atribuye a la decadencia de la mayúscula que se había barroquizado, a la influencia del libro y a que el mensaje se hace más prolijo ${ }^{50}$. Este tipo de letra continuará utilizándose hasta bien entrado del siglo XVI y parte del siglo XVII.

El número de inscripciones en letra gótica minúscula aumenta respecto a las anteriores. Ello es lógico, en la Baja Edad Media el hecho escriptorio en general se multiplica -documento y libro-, ya que la capacidad de leer y escribir se extiende a otros estamentos de la sociedad, además del clero, a la nobleza y a la burguesía. Serán precisamente estos últimos los que van a irrumpir en el ámbito publicitario con una fuerza desconocida anteriormente.

Por otra parte, la tipología de las inscripciones amplía su abanico. Continúa habiendo Funera en general, aunque desaparecen los Epitaphia necrologica, de tal manera que tendremos los tradicionales Epitaphia sepulcralia y un nuevo tipo epigráfico los Tituli proprietatis sepulturae. También apreciamos como el número de inscripciones librarias aumenta en estas fechas.

La escritura gótica minúscula aparece en Salamanca con el siglo XV. Si bien contamos con dos ejemplos: el Funus de Diego López, arcediano de Ledesma, localizado en la catedral vieja de Salamanca ${ }^{51}$ y el Epitaphium sepulcrale del obispo Pedro Díaz, en la catedral de Ciudad Rodrigo ${ }^{52}$ que podemos fechar en torno a 1342 y 1343 respectivamente. Sin embargo, la carencia de fecha en el primer caso $^{53}$ y la escritura anacrónica del segundo, nos hacen sospechar que se trata de

\footnotetext{
${ }^{49}$ N. RODRÍGUEZ SUÁREZ (2010). "Paleografía epigráfica: La transición hacia la letra gótica minúscula en las inscripciones españolas”. En V. García Lobo y $M^{a}$. E. Martín López (coords): Las inscripciones góticas. II Coloquio Internacional de Epigrafia Medieval, León: Corpus Inscriptionum Hiispaniae Mediaevalium, pp. 469-477. (= N. RODRÍGUEZ SUÁREZ (2010). "Paleografía”).

${ }^{50} \mathrm{M}^{\mathrm{a}}$. E. MARTÍN LÓPEZ (1999). "La escritura publicitaria en la Península Ibérica. Siglo XV”: En Ch. Steininger, W. Koch, Inschrift und material Inschrift und Buchschrift. Fachtagung für mittelalterliche und neuzeitliche Epigraphik Ingolstadt 1997, München:Taschenbuch, p. 192. (= M E. MARTÍN LÓPEZ (1999). "La escritura").

${ }^{51}[\ldots]$ dominus Didacus Lupo archi[diaconus de Ledesma...].

${ }^{52}$ Aqui yaze el obispo don Pedro Diaz, que resucito san Francisco.

${ }^{53}$ A. C. S. caj. 3, leg. 2, no 4 y 14. Sabemos que este personaje murió con anterioridad al mes de abril de 1342, en la que según la documentación los bienes de este personaje se estaban repartiendo
} 
copias o de originales tardíos. Aunque es preciso advertir que, sabemos que esta escritura se usaba ya desde mediados del siglo XIV en otras zonas el territorio hispánico, por lo que quizás podríamos adelantar a esas fechas la introducción de la gótica minúscula también en Salamanca ${ }^{54}$.

Lo que no cabe duda es que ya a inicios del siglo XV la escritura gótica minúscula aparece perfectamente asentada en la zona. Del año 1401 es el Titulus proprietatis de la sepultura de Alfonso Sánchez de Ávila, en la iglesia de Santa María de los Caballeros ${ }^{55}$ y anterior sería el epígrafe, carente de data, que acompaña a las pinturas de las escenas de san Gil, en el convento de Santa Clara y que los especialistas fechadas en $1391^{56}$.

Entre las características gráficas alfabéticas generales de este tipo de escritura podemos señalar que se trata de la que venimos llamando letra gótica minúscula solemne o caligráfica, que aún conservando sus características, va evolucionando a medida que nos acercamos al siglo $\mathrm{XVI}^{57}$. Al avanzar el siglo, las letras tienden a formarse por la unión de varios trazos rectos. Los casos más representativos, en este sentido, son la M, formada por tres trazos que no llegan a unirse (ejemplo 2) o la $\mathrm{N}$ con los dos trazos independientes (ejemplo 1 y 3 ). En ocasiones, tampoco llegan a cerrarse letras como la B (ejemplo 3), la P (ejemplo 1), o la Q. Desaparecen los bucles redondeados que son sustituidos por líneas horizontales y verticales.

Como signo general de abreviación se usa la línea sobrepuesta que, en ocasiones, suple solamente a la nasal o a la E, lo que supone que el uso de la abreviatura por contracción sea el más utilizado.

Encontramos el empleo de letras sobrepuestas, que en muchas ocasiones se emplean como abreviación. Así se aprecia en las palabras Alfonso (å) y Sánchez (SZ), en la Roboratio de Alfonso Sánchez de Ávila, en la iglesia de Santa María de los Caballeros en Salamanca ${ }^{58}$ o en el Epitaphium sepulcrale de García

entre sus herederos.

${ }^{54}$ N. RODRÍGUEZ SUÁREZ (2010). "Paleografía".

${ }^{55}$ Sepultura del dotor Alfonso Sanchez de Avila oydor del rrey fiio de Pero Sanchez cavallero. Fallecio ano de mil e quatrocientos uno.

${ }^{56}$ F. GUTIÉRREZ BAÑOS (2005). Aportación al estudio de la pintura de estilo gótico lineal en Castilla y León: Precisiones cronológicas y corpus de pintura mural y sobre tabla, vol. II, Madrid: Fundación Universitaria Española, 208. (=F. GUTIÉRREZ BAÑOS (2005). Aportación).

${ }^{57}$ Ma. E. MARTÍN LÓPEZ (1999). “La escritura”, pp. 191-206.

${ }^{58}$ Estas tres sepulturas mando fazer el dotor Antonio Sanchez de Avila, oydor del rrey, para si e para el dotor Antonio Ruiz, su suegro, e para Leonor Sanchez Guedeja, muger del dicho Antonio Sanchez de Avila dotor, la qual fallecio año de mil cuatrocientos cincuenta años. 
Brochero, en la iglesia de San Juan de Alba de Tormes ${ }^{59}$ que emplea esta técnica de abreviación en numerosas palabras " $A q^{i}$ ", " $b^{o} r$ " etc, llegando a resultar, en cierto modo, un elemento decorativo de la inscripción, que se emplea incluso cuando no es necesario, como en mayo " may $^{\circ} \mathrm{o}$ ".

Como signos especiales tenemos el de PER y el de -US. La p partida ( $p$ ) se emplea en las Explanationes de la coronación de la Virgen de Fernando Gallego ${ }^{60}$ "sup" y en el Titulus proprietatis de Pedro Hernández Maldonado, en la iglesia de San Benito de Salamanca ${ }^{61}$, en el que para abreviar el nombre de este personaje se emplea este signo "po" para Pero.

El signo especial de -US, en forma de pequeña coma invertida, se emplea únicamente en cuatro epígrafes. Lo encontramos en las Explanationes del retablo de la catedral vieja de Salamanca, en la unción de Betania "iud" y en el prendimiento de Jesús " $s$ ' pet", en las Explanationes de la Virgen de la Rosa, obra de Fernando Gallego ${ }^{62}$, "domin" y en las Explanationes de la coronación de la Virgen del mismo autor " $e i$ " "an".

Las notas tironianas se reducen al signo de et que se convierte ahora en una $\mathrm{T}$ con bucle.

Los recursos publicitarios, de nuevo, son escasísimos se reducen al signo st como el que aparece en la Roboratio descontextualizado de una sacristía, situada hoy en el zaguán del ayuntamiento de Ciudad Rodrigo ${ }^{63}$.

\footnotetext{
${ }^{59} \mathrm{~A}$ : Aqui yaze el onrrado cavallero Garcia Brochero, iio de Iuan Brochero el mayor. Falle[c $\left.{ }^{\mathrm{c}} \mathrm{i}\right]$ dos de hebrero de mil quatrocientos sesenta y cuatro annos .

B: Aqui yaze Costanca Martinez de Gonsalvo muger de Garcia Brochero. Fallecio a dies de otobre mil quatrocientos ochenta y cinco.

${ }^{60} \mathrm{~A}$ : corona aurea super caput eius

B: Esechias: corona tua çircunligata sit tibi vigesimo quarto

C: Ysayas: et erit (sic) corona gloriae in manu Domini sesto capitulo

D: posuisti incapite eius coronam de lapide precioso. Psalmo trigesimo David

E: sponssabo te michi in sem piternum. secundo capitulo Oseas

F: Ieremias: reaciacula et malogranate super coronam in circuito

$\mathrm{G}$ : in perpetuum coronata triumphat sapiencie. quarto Salamon

$\mathrm{H}$ : ecce anus Dei quitollis pecata mundi

${ }^{61}$ [Sepultura] del honrado cavallero Pero Hernandez Maldonado, que Dios haya...

${ }^{62} \mathrm{~A}:[\mathrm{v}] \mathrm{i}[\mathrm{r}] \mathrm{go}$ concipiet et pariet filium.

B: David descendit dominus sicut pluuia in velus.

C: AW UIOTA RB3ENOCVBI

D: UᄀiAVRT 3EIL Ж ABACDEFG O

E: FERNANDVS GALECVS

${ }^{63}$ Esta sacristia mandaron fazer los feligreses desta iglesia año de mil quatrocientos ochenta al qual fenecio la guerra entre el rey don Fernando e la reyna dona Ysabel de Castilla contra el rey don
} 
Tabla 5. Alfabetos en escritura gótica del siglo XV. Elaboración propia.

\section{Escrıtura Gotıca XV}

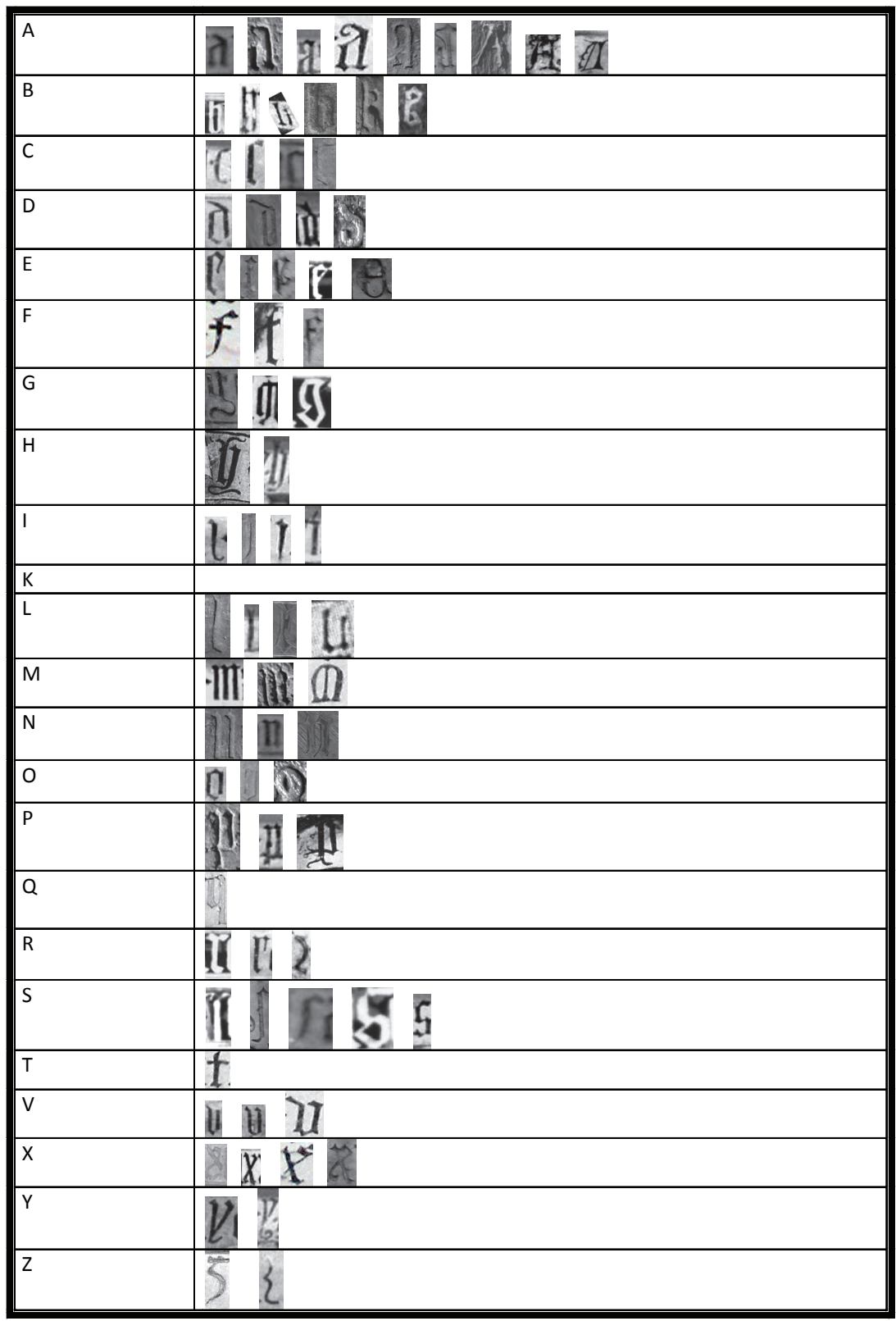

Alonso de Portogal y se asentaron las pazes entre ellos. 


\section{INSCRIPCIONES PREHUMANÍSTICAS.}

La crisis de las escrituras góticas librarias y documentales alcanzó también el campo publicitario. Ya habíamos visto cómo la letra mayúscula, tradicionalmente predominante en este campo, cedió por completo ante la minúscula caligráfica. La inquietud humanista que desembocará en la resurrección de la olvidada escritura carolina, dará como resultado -ciertamente provisional- una escritura publicitaria híbrida, cuyo alfabeto se formará a base de mayúsculas rescatadas de las escrituras anteriores, en nuestro caso la visigótica, la carolina y la propia gótica ya olvidada ${ }^{64}$. Nos situamos en el último cuarto del siglo $\mathrm{XV}^{65}$

En Salamanca los ejemplos alcanzan un número de catorce inscripciones que emplean este tipo de escritura.

Presenta dos variedades. La primera se caracteriza por la combinación de alfabetos anteriores sin añadirles ningún artificio. La encontramos en la Casa de las Conchas de Salamanca, tanto en la reja de la ventana como en los lambrequines del escudo ${ }^{66}$. En este modelo se retoma la letra mayúscula, concretamente la carolina que los intelectuales recuperan en su búsqueda de claridad. Pero junto a ella, vemos también letras capitales como la $\mathrm{D}$ y diversas letras de otros alfabetos, como la P de PLENA o la M usada en el lambrequín que parece una reinterpretación de formas anteriores

Ilustración 2 Detalle de la Invocatio en la Casa de las Conchas. (Archivo propio)..

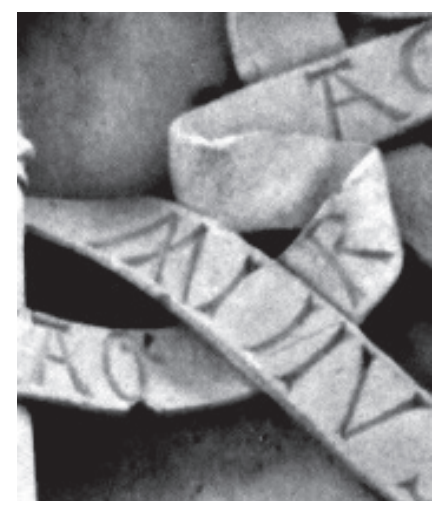

\footnotetext{
${ }^{64}$ Basta consultar el cuadro VII para comprobarlo de una manera clara y de conjunto.

${ }^{65}$ Sobre la escritura prehumanística puede consultarse: W. KOCH (1996). "Inscripciones y estudios epigráficos de los países de lengua alemana". Estudios humanisticos geografia, historia, arte, 18, p. 161-182. (=W. KOCH (1996). "Inscripciones").

${ }^{66}$ Ave Maria gratia plena, Dominus tecum benedicta tu in, en una y en la otra: Ave Maria, gracia plena, dominus tecun.
} 
Otra variedad se caracteriza por el empleo de alfabetos anteriores pero alterando ciertas letras con elementos decorativos o seleccionando aquellas que ya los poseían. Es la que presenta la Hortatio a la concordia en la Casa de las Batallas $^{67}$ o los lambrequines del escudo de una hornacina, en la claustro de la catedral vieja de Salamanca ${ }^{68}$. Son, de nuevo, letras mayúsculas retomadas de distintos alfabetos, generalmente unciales. Esta modalidad es más esbelta y decorada, pues utiliza trazos, puntos y formas sinuosas innecesarias, cuya finalidad es puramente decorativa.

Ilustración 3 y 4 Detalle escritura prehumanistica. (Archivo propio).
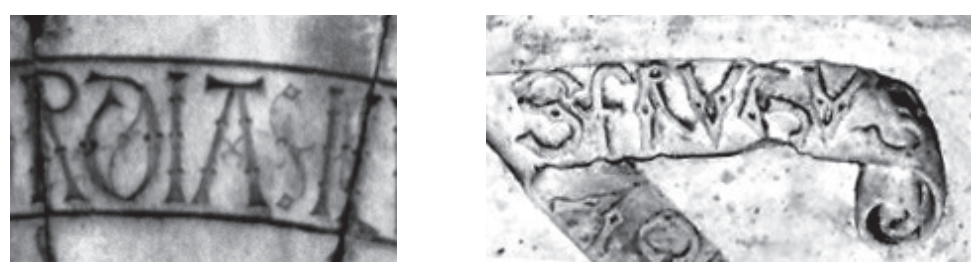

El conjunto de abreviaturas empleadas en este tipo de inscripciones muestra una utilización de los tres sistemas tradicionales, así se aprecia, por ejemplo, en palabras como Fernandus (FERNÃDUS) de las Explanationes y Suscriptio del pintor Fernando Gallego en el tríptico de la Virgen de la Rosa, gloria GL̃IA en la Explanatio del nacimiento de Cristo, en la catedral de Salamanca ${ }^{69}$ o el manifestentur (MANIFESTẼTUR) del retablo de la catedral de Ciudad Rodrigo. El sistema de suspensión lo encontramos en palabras como misa (M) del Mandatum de Pedro Juanes, en la iglesia de Nuestra Señora de la Asunción de Almenara de Tormes $^{70}$ o en el in (I) del retablo de la catedral de Ciudad Rodrigo y también en la a que seguramente respondería a la abreviatura de algún nombre, que observamos en ese mismo retablo. La contracción se observa en Ihoannes (IH̃NS) del Mandatum de Pedro Juanes o en el retablo de la catedral de Ciudad Rodrigo en Jerusalén (IHRLM̃), El sistema mixto se emplea o (MA) para meas.

El signo especial de per que se emplea en la palabra opera del retablo de la catedral de Ciudad Rodrigo OPA, y en el Mandatum de Pedro Juanes que desarrolla el tradicional signo de pro con valor per.

Estas inscripciones carecen del empleo de los recursos publicitarios.

\footnotetext{
${ }^{67}$ Ira odium generat, concordia nutrit amoren.

68 (Cruz) Ave Maria gracia plena dominus tecum beneditus frutus.

${ }^{69}$ Gloria in ex[celsis].

${ }^{70}$ Petro Ihoanes mando quatro misas pro sua anima
} 
Tabla 6. Alfabetos en escritura prehumanistica. Elaboración propia.

\section{Escritura prehumanística}

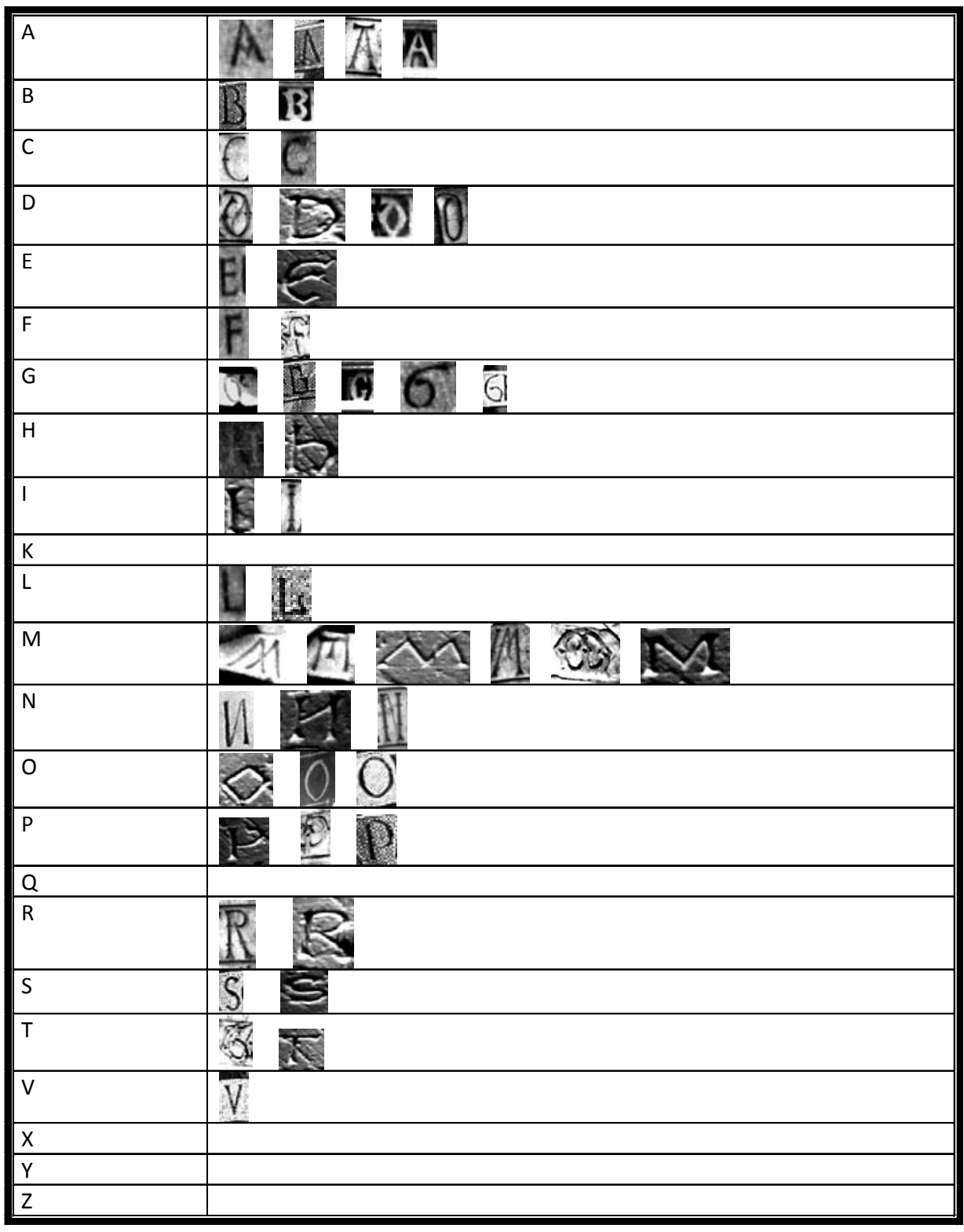




\section{BIBLIOGRAFÍA}

ALONSO ÁVILA, A. Y CRESPO ORTIZ DE ZARATE, S. (1999). Corpus de inscripciones romanas de la provincia de Salamanca: Fuentes epigráficas para la historia social de la Hispania Romana. Valladolid: A. Alonso, S. Crespo.

ALDEA, Q. MARÍN MARTÍNEZ, T. y VIVES, J. (1975). Diccionario de historia eclesiástica de España, Madrid: C.S.I.C.

AA.VV. (1999). Deutsche inschriften. Terminologie zur Schriftbeschreibung. Viena: Akademie der Wissenchaften in Wien.

BARROCA, M. J. (2000). Epigrafía medieval portuguesa (862-1422), vol I. Oporto: Fundaçao Calouste Gulbenkian.

DEBIAIS, V. (2009). Messages de Pierre. La lectura des inscriptions dans la communication médiévale. Turnhout: Brepols.

DESCHAMPS. P. (1929). Étude sur la paléographie des inscriptions lapidaires de la fin de l'époque mérovingienne aux dernières années du XIII ${ }^{e}$ siècle. Paris.

DURÁN GUDIOL, A. (1967). Las inscripciones medievales en la provincia de Huesca: Estudios de la Edad Media de la corona de Aragón, vol. VII. Zaragoza: Escuela de estudios medievales.

GARCIA LOBO, V. (1982). Las inscripciones de San Miguel de Escalada: estudio crítico. Barcelona: El Albir.

Ídem. (1999). "La escritura publicitaria en la Península Ibérica. Siglos X-XIII“. En Ch. Steininger, W. Koch, Inschrift und material Inschrift und Buchschrift. Fachtagung für mittelalterliche und neuzeitliche Epigraphik Ingolstadt 1997. München:Taschenbuch, pp. 155-190.

GARCÍA LOBO, V. y MARTÍN LÓPEZ, Ma . E. (1995). De Epigrafía Medieval. Introducción y Álbum. León: Universidad de León.

GÓMEZ MORENO, M. (1953). El concepto de la epigrafia. Consideraciones sobre la necesidad de su ampliación. Discursos leídos ante la Real Academia de la Historia por los señores D. Joaquín $M^{a}$. de Navascués y de Juan y D. Manuel Gómez-Moreno y Martínez en la recepción pública del primero, el día 18 de enero de 1953. Madrid: Real Academia de la Historia.

GONZÁleZ DÁVILA, G. (1606). Historia de las antigüedades de la ciudad de Salamanca: vida de sus obispos y cosas sucedidas en su tiempo, Salamanca: Artus Taberniel. (ed. 1994)

GUTIÉRREZ ÁlVAREZ, M. (1999). Corpus Inscriptionum Hispaniae Mediaevalium. Zamora. Estudio, I/2. Turnhout-León: Brepols. 
GUTIÉRREZ BAÑOS, F. (2000). Pinturas de estilo gótico lineal en Castilla y León En: XIII Congreso Nacional de Historia del Arte. Ante el nuevo milenio: raíces culturales, proyección y actualidad del arte español. Granada 31 de octubre- 3 de noviembre, vol II, pp. 1102-1105. Granada: Universidad de Granada.

Ídem. (2005). Aportación al estudio de la pintura de estilo gótico lineal en Castilla y León: Precisiones cronológicas y corpus de pintura mural y sobre tabla, vol. II. Madrid: Fundación Universitaria Española.

HERNÁNDEZ GUERRA, L. (2001). Epigrafía de época romana en la provincia de Salamanca, Valladolid: Centro Buendía. Universidad de Valladolid.

HÜBNER, A. (1869). Inscriptiones Hispaniae Latinae, vol. II. Berlín.

KOCH, W. (1996). "Inscripciones y estudios epigráficos de los países de lengua alemana”. Estudios humanísticos geografia, historia, arte, 18, p. 161-182.

MARTÍN LÓPEZ, Ma . E. (1999). "La escritura publicitaria en la Península Ibérica. Siglo XV": En Ch. Steininger, W. Koch, Inschrift und material Inschrift und Buchschrift. Fachtagung für mittelalterliche und neuzeitliche Epigraphik Ingolstadt 1997. München: Taschenbuch, pp. 191-206.

Ídem. (1999). "La escritura publicitaria en la Península Ibérica. Siglo XV“. En Ch. Steininger, W. Koch. Inschrift und material Inschrift und Buchschrift. Fachtagung für mittelatterliche und neuzeitliche epigraphik. Ingolstadt 1997. München: Taschenbuch, pp. 191-206.

MARTÍN LÓPEZ, Ma . E. y GARCÍA LOBO, V. (Coords). (2010). Las inscripciones góticas. II Coloquio Internacional de Epigrafía medieval. León del 11 al 15 de septiembre 2006. León: Corpus Inscriptionum Hispaniae Mediaevalium.

RODRÍGUEZ SUÁREZ, N. (2010). "Paleografía epigráfica: La transición hacia la letra gótica minúscula en las inscripciones españolas”. En V. García Lobo y $M^{a}$. E. Martín López (coords). Las inscripciones góticas. II Coloquio Internacional de Epigrafia Medieval. León: Corpus Inscriptionum Hispaniae Mediaevalium, pp. 469-477.

Ídem. (2012). "Un repaso a través de los conceptos de epigrafía e inscripción”: Documenta \& Instrumenta, 10, 29-36.

VILLAR GARCÍA, L. M. (1986). La Extremadura Castellano-Leonesa, guerreros, clérigos y campesinos (711-1250). Valladolid: Junta de Castilla y León. 